LET: Linguistics, Literature and English Teaching Journal

|Volume||11||Issue||1||Pages||20-41||2021\|

|P-ISSN: 20869606 ; E-ISSN:25492454|

Available online at: http://jurnal.uin-antasari.ac.id/index.php

\title{
ENGLISH PRONUNCIATION DIVERSITY PRODUCED BY INDONESIAN COVER-SINGERS: A CASE STUDY ON THE YOUTUBE CHANNEL
}

\author{
Ismi Maulina Utami \\ ismi.17020154029@mhs.unesa.ac.id \\ Universitas Negeri Surabaya
}

\begin{tabular}{l} 
Article History: \\
Received: 12 April 2021 \\
Accepted: 20 June 2021 \\
\hline
\end{tabular}

This study focused on the pronunciation changes of the Indonesian cover-singers on YouTube. It was qualitative research by using documentation technique. There were three subjects of this study namely RM with song "Memories", AH with song "Thank You Next", and HD with song "Comethru". At the first singer's pronunciation, there were 26 mispronounced words and she did consonant deletion, vowel shift, consonant neutralization, vowel coalescence, consonant insertion,

\section{Keywords:}

Pronunciation changes;

Segmental; Indonesian cover-singers and metathesis. At the second singer's pronunciation, there were 17 mispronounced words and she did consonant deletion, vowel shift, consonant neutralization, consonant insertion, assimilation, and diphthongization. At the third singer's pronunciation, there were 12 mispronounced words and she did consonant deletion, consonant neutralization, vowel shift, vowel coalescence, and consonant insertion. These pronunciation changes occured because of the distinction between the phonological system of English and Bahasa Indonesia, and the Indonesian cover-singers still relied on the word's spelling rather than phonetic sound. Regardless of these two reasons, there were also several similarities in the phonological system between English and Bahasa Indonesia, but the Indonesian cover-singers still performed the pronunciation changes. 


\section{INTRODUCTION}

English has become a global language that is used by people throughout the world, especially in Indonesia. Nowadays, English not only becomes a means of communication to overcome language distinction, but it can also be a means of expression in arts, one of the arts is in a song. In the modern era, many English songs have sprung from various genres ranging from pop, jazz, alternative rock, blues, metal, and many more. With the help of technological advances, English songs can be listened to by Indonesian people on social media like YouTube. Not only listen to English songs, but Indonesian people also often re-sing the English songs that are sung by the English original singers which they then upload their cover videos on YouTube. In this case, Indonesian people who like to re-sing English songs in YouTube are called Indonesian cover-singers. In singing English songs, those Indonesian cover-singers as much as possible try to equate the pronunciation performed by English original singers. However, there are some sounds that cannot be pronounced fluently by them until it resulted in the pronunciation changes.

The phenomenon of pronunciation changes can occur because Indonesian cover-singers do not use English as their first language, but they tend to use Bahasa Indonesia. In addition, the distinction in the phonological system between English and Bahasa Indonesia also becomes the cause of Indonesian cover-singers to produce pronunciation changes. Actually, Bahasa Indonesia and English have 26 alphabetical letters, but both have different ways of pronouncing them. Alwi et al. (2017) states that Bahasa Indonesia has 35 sounds that consist of 22 consonants, 10 vowels, and 4 diphthongs. Whereas English has 42 sounds which consist of 25 consonants, 12 vowels, and 5 diphthongs (Fromkin et al., 2014). Moreover, Pallawa (2013) reveals that the sounds $[æ],[\Lambda],[3],[v],[\theta],[ð]$ exist in English, but they are absent in the Bahasa Indonesia phonological system. Meanwhile, Martin (2004) states that there is no relation between the sound and letter in English. Avery (2013) also adds that the English spelling system reveals many examples of the discrepancy between spelling and sounds. Some of English letters have more than one sound. It is noticeable that the sound [c] in the word "car" and "city" can be pronounced 
differently by the speaker. Unlike English, the sound and letter in Bahasa Indonesia have a very close relationship. For example, the letter "a" in Bahasa Indonesia also represents sound [a].

The distinction of the phonological system between Bahasa Indonesia and English may result in phonological processes. Wolfram and Johnson (1984) states that a dynamic system in which units change as they come into contact with other units in the system is called a phonological process. According to Schane (1973), there are some variations of the English phonological process namely assimilation, syllable structure, weakening and strengthening, and neutralization.

There are three previous studies that examine the pronunciation changes produced by singers when they sing English song. Wahyuni (2012) proves in her study that Korean singers are difficult to produce labiodental fricative sounds, such as [f] and [v] and they also do the 8 strategies to overcome the pronunciation changes, such as substitution, deletion, assimilation, insertion, simplification, consonant clusters, syllable position, and gemination. In addition, Jelangpaska (2020) conducts a study with one of the Indonesian bands named Klif is used as the subject. The study finds that the 9 sounds, such as $[1],[\mathrm{r}],[\mathrm{t}],[\mathrm{d}],[\mathrm{k}],[\mathrm{z}],[\mathrm{n}]$, and [n] are pronounced differently by the vocalist as well as the two phonological process namely assimilation and deletion. Moreover, Khumaidi (2020) analyzes the pronunciation changes produced by metal vocalists. The study reveals that the metal technique used by the metal vocalists affects them to do the pronunciation changes and each of the metal vocalists do segment substitution, insertion, and deletion. It also finds that the impact of the application of the metal vocal technique makes the pronunciation of the vocalists difficult for listeners to hear it clearly.

Unlike those previous studies, this study will observe and discuss the pronunciation changes produced by Indonesian cover-singers when they are singing English songs on the YouTube channel as well as the type of phonological process. As it is known that the Indonesian cover-singers do not use English as their mother tongue and there are some differences on segmental features between Bahasa Indonesia and English. The problem limitation on aspects that will be discussed in 
this study is a phonological system with a focus on segmental features and also the phonological process. This problem limitation leads to several questions to be discussed further, namely 1). To what extent do the pronunciation of Indonesian cover-singers when they sing English songs on the YouTube channel? 2). What are the phonological processes that caused English pronunciation diversity produced by Indonesian cover singers on the YouTube channel?

As for the significance purpose, this study tries to elaborate the distinction of the phonological system between English and Bahasa Indonesia, and it is also expected that this study will improve the Indonesian singers' awareness in singing English songs with correct pronunciation.

\section{Segmental Features}

According to (Fraser, 2001; Carr, 2008), the study of the segmental features includes vowels and consonant allophones. Odden (2005) explains that a consonant is a sound other than a vowel. It is produced by restriction in the human vocal tract that blocks the airflow. In reverse, Fromkin et al (2014) states that the vowel is formed through the mouth and/or the nose with little restriction of airflow from the lungs. Meanwhile, Yule (2006) defines diphthong as the combination between vowel sounds. In English, there are 43 sounds which consist of 25 consonants, 12 vowels, and 5 diphthongs (Fromkin et al., 2014). The English consonants are [p], $[\mathrm{b}],[\mathrm{t}],[\mathrm{d}],[\mathrm{k}],[\mathrm{g}],[\mathrm{f}],[\mathrm{v}],[\mathrm{e}],[\mathrm{d}],[\mathrm{s}],[\mathrm{z}],[\mathrm{S}],[3],[\mathrm{h}],[\mathrm{t}]],[\mathrm{d} z],[\mathrm{m}],[\mathrm{n}],[\mathrm{\eta}],[1]$, $[\mathrm{r}],[\mathrm{w}],[\mathrm{M}]$ and $[\mathrm{j}]$. In term of vowel and diphthong, the English sounds are [i], [I],

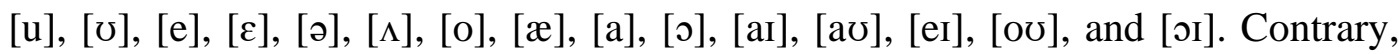
Alwi et al. (2017) states that there are 32 sounds consists of 22 consonants, 10 vowels, and 4 diphthongs in Indonesian. The Bahasa Indonesia consonants are [p], $[\mathrm{b}],[\mathrm{t}],[\mathrm{d}],[\mathrm{c}],[\mathrm{j}],[\mathrm{k}],[\mathrm{g}],[\mathrm{f}],[\mathrm{s}],[\mathrm{J}],[\mathrm{z}],[\mathrm{h}],[\mathrm{m}],[\mathrm{n}],[\mathrm{n}],[\mathrm{\eta}],[\mathrm{r}],[\mathrm{l}],[\mathrm{w}],[\mathrm{x}]$, and [y]. In term of vowel and diphtong, the Bahasa Indonesia sounds are [i], [I], [u], [v], $[\mathrm{e}],[\varepsilon],[ə],[o],[\mathrm{a}],[0]$, ai], [au], [oi], and [ei]. In conclusion, the English sounds $[\mathrm{v}],[\Theta],[ð],[\Lambda],[æ],[\mathrm{o \mho}]$, and [эг] are absent in the Bahasa Indonesia phonological system. 


\section{Phonological Process}

Phonological process is a process that occurs when a unit of sounds in a language changed to another sound in a system of language. Schane (1973) divides phonological processes into 4 , namely assimilation, syllable structure, weakening and strengthening, and neutralization.

\section{Assimilation}

It is a process that makes the sound similar to the neighbor sounds. According to Schane (1973), there are 4 types of assimilation. First, consonant assimilates vowel features, it is a process when a vowel's characteristics can be applied to a consonant as secondary alterations, e.g. the word electric becomes electricity. Here, the sound $[\mathrm{k}]$ is pronounced as sound $[\mathrm{s} /]$ when it is followed by schwa. Second, vowel assimilates consonant features, it is a process when a vowel is superimposed into a consonant feature, e.g the sound [i] is nasalized in the word seen. Third, consonant assimilates consonant features, it is a process when a consonant takes to feature in another consonant, e.g. got me is pronounced as [ga:m mi] instead of [ga:t $\mathrm{mi}]$. Here, the sound [t] takes to feature in sound $[\mathrm{m}]$ to make the words easier to be pronounced. Fourth, vowel assimilates vowel features, it is a process when a vowel becomes more like another vowel, e.g. in Turkish, there are dis (house) and disim (my house).

\section{Syllabic Structure Process}

According to Schane (1973), there are some types of syllabic structure process. Deletion is a process in which a sound segment lost in others. It can occur in both consonants and vowels. For example, the sound [s] is omitted as in he's made. Insertion is a process of adding a sound segment into a word. It can occur in both consonants and vowels. An example of insertion is when a schwa [ə] is inserted in a word grow [gərov]. Coalesence is a process in which two or more sounds can be replaced by one sound. It can occur in both consonants and vowels. The example is when consonant [d] and [j] are adjacent to consonant [dz] in would you. Major class feature is a process when there is a change of segment in major class membership, 
e.g. the vowel [i] becomes consonant [j] in pavilion. Metathesis is a process that occurs when the two segments reverse position. It can be found as people pronounce [æsk] instead of [æks].

\section{Weakening and Strengthening}

Schane (1973) states that weakening and strengthening occur when a shift in a simple syllabic structure contributes to a complex syllable structure and vice versa. There are some types of weakening and strengthening process. Syncope refers to a condition when a vowel near a stressed vowel is deleted e.g, chocolate becomes choc'late. Meanwhile, apocope refers to a condition when there is a loss of the final unstressed vowel. The most common example of apocope is a schwa reduction, like an animal is pronunced as [ænıml] instead of [ænı $\mathrm{m}(\curvearrowright) 1]$. Vowel reduction is a process in which unstressed vowel become schwa, e.g. banana is pronounced as [bə'nænə]. Next, dipthongization is a term used to indicate the change of vowel sound to diphthong sound, e.g. tin is pronunced as [tain] instead of [tin]. Then, vowel shift is a process when a stressed vowel can change the position of the vowel structure. For example, the word these is pronunced as [ðеz] instead of [ðı]].

\section{Neutralization}

Schane (1973) defines neutralization as a process that occurs if there is a cancellation of contrasts between the phonological unit in the specifed environment. It can occur in both consonants and vowels. The example of neutralization is when the consonant $[\mathrm{d}]$ is devoiced into consonant $[\mathrm{t}]$ in the final sound.

\section{METHOD}

The qualitative method was used in this study because the result is properly conveyed in the form of detailed text. According to Hancock and Algozzine (2006) qualitative is a type of research method that requires interviews, focus groups, observation, and review of existing documents as a rich source of data. The goal is to recognize the phenomena that occur in the subject of this study. There were three subjects in this study, their names were abbreviated to maintain their confidentiality. They were RM, AH, and HD. Those subjects were chosen since they liked to cover 
both English and Indonesian songs on the YouTube channel. In addition, they got a lot of viewers on their cover videos, which was over 300 thousand views and they also had a different pronunciation with the original singers when they sang the selected English songs in this study. Here, the writer had selected the songs sung by American singers, because the American English accent was used as guidance in this study. The first singer was RM who sang "Memories" by Maroon Five. The second singer was AH who sang "Thank You Next" by Ariana Grande. The third singer was HD who sang "Comethru” by Jeremy Zucker.

In this study, documentation was used as a technique to collect the data because the form of data is in audio files of Indonesian cover-singers taken from YouTube and the transcript of the song's lyrics. The three audio files were gathered from the three different YouTube channels. Furthermore, the researcher was used as the intsrument to collect and interpret the data of this study. In the matter of analyzing a data, this study followed the data analysis technique by Miles et al. (2014), namely data condensation, data display, drawing and verifying conclusions.

\section{FINDINGS AND DISCUSSIONS}

\section{The Pronunciation of Indonesian Cover-singers}

The First Indonesian cover-singer (RM)

The first Indonesian cover-singer named RM sung the song titled "Memories" by Maroon five and there were 26 words that pronounced differently by her.

Table 1. The list of the first Indonesian cover-singer's pronunciation

\begin{tabular}{|c|c|c|c|}
\hline No. & English Words & $\begin{array}{l}\text { The Original Singer } \\
\text { Pronunciation }\end{array}$ & $\begin{array}{l}\text { The First Indonesian } \\
\text { Cover-singer's } \\
\text { Pronunciation }\end{array}$ \\
\hline 1 & Here's & [hIrz] & [hiz] \\
\hline 2 & The & [ðə] & [ðひ] \\
\hline 3 & Ones & [wınz] & {$[\mathrm{w} \wedge \mathrm{n}]$} \\
\hline 4 & Cheers & {$\left[\mathrm{t} \int \mathrm{Irz}\right]$} & {$\left[\mathrm{t} \int \mathrm{Is}\right]$} \\
\hline
\end{tabular}

Ismi Maulina Utami 


\begin{tabular}{|c|c|c|c|}
\hline 5 & Cause & [koz] & [kos] \\
\hline 6 & Drinks & drınks] & [drınk] \\
\hline 7 & Toast & [toust] & [tus] \\
\hline 8 & Here & [hir] & [h3r] \\
\hline 9 & Lost & [lost $]$ & [los $]$ \\
\hline 10 & Back & [bæk] & [bek] \\
\hline 11 & Been & [bin] & {$[\mathrm{b} \varepsilon \mathrm{n}]$} \\
\hline 12 & There's & [ðعrz] & [ð $\varepsilon \mathrm{s}]$ \\
\hline 13 & No & [nov] & [nof] \\
\hline 14 & Stay & [steI $]$ & [seI] \\
\hline 15 & Same & [seIm] & {$[\mathrm{sem}]$} \\
\hline 16 & Now & [nav] & [no] \\
\hline 17 & Hurts & [herts] & [het] \\
\hline 18 & Of & {$[\Lambda \mathrm{v}]$} & [of] \\
\hline 19 & Sometimes & {$[\mathrm{s} \Lambda \mathrm{m}, \operatorname{tarmz}]$} & {$[\mathrm{s} \Lambda \mathrm{m}$, taim $]$} \\
\hline 20 & Through & {$[\theta \mathrm{ru}]$} & {$[\theta$ rut $]$} \\
\hline 21 & Felt & {$[\mathrm{f} \varepsilon \mathrm{lt}]$} & [flet] \\
\hline 22 & Hatred & [heitrid] & [hetret] \\
\hline 23 & An & [æn] & [ə] \\
\hline 24 & It's & [Its] & [Is] \\
\hline 25 & Never & [nevər] & [ncfər] \\
\hline 26 & Gone & [gon] & [go] \\
\hline
\end{tabular}


In the word here's, the consonant [r] was deleted. The vowel [ə] was substituted with vowel $[\mho]$ in the word the. In the word ones, the consonant [z] was deleted. Then, in the word cheers, the consonant [r] was deleted and the consonant [z] is substituted with consonant [s]. The consonant [s] in the word drinks was deleted. Meanwhile, in the word toast, the diphthong [ov] was substituted with vowel $[\mathrm{u}]$ and the consonant $[\mathrm{t}]$ was also deleted. The vowel $[\mathrm{I}]$ was substituted with vowel [3] in the word here. In the word lost, the consonant [t] was deleted. The vowel [ae] in the word back was substituted with vowel [e]. The vowel [i] was substituted with vowel $[\varepsilon]$ in the word been. Other than that, the consonant $[r]$ was omitted in the word there's. The consonant [f] was inserted at the last word of no. The consonant [t] was deleted in the word stay. The diphthong [er] was substituted with vowel [e] in the word same. Meanwhile, the diphthong [av] was substituted with vowel $[\mathrm{o}]$ in the word now. The consonant $[\mathrm{r}]$ and $[\mathrm{s}]$ were deleted in the word hurts. The vowel $[\Lambda]$ was subtituted with vowel [o] and the consonant [v] was also substituted with consonant [f] in the word of. In the word sometimes, the consonant [z] was deleted. Besides that, the consonant [t] was inserted at the end of the word truth. The word felt was pronounced as [flet] instead of [felt]. The diphthong [eI] was substituted with vowel $[\varepsilon]$ and the vowel [I] was also substituted with vowel [e] in the word hatred. In the word an, the consonant [n] was deleted. In the word it's, the consonant $[\mathrm{t}]$ was also deleted. The consonant $[\mathrm{v}]$ was substituted with consonant [f] in the word never. The last, the consonant [n] was deleted in the word gone.

The Second Indonesian cover-singer (AH)

The second Indonesian cover-singer is AH. She sung the song titled "Thank You Next" by Ariana Grande and there were 17 words that pronounced differently by her. 
Table 2. The list of the second Indonesian cover-singer's pronunciation

\begin{tabular}{|c|c|c|c|}
\hline No & English Words & $\begin{array}{l}\text { The Original Singer } \\
\text { Pronunciation }\end{array}$ & $\begin{array}{l}\text { The Second Indonesian } \\
\text { Cover-singer's Pronunciation }\end{array}$ \\
\hline 1 & Got & [gat] & [get] \\
\hline 2 & Married & [mærid] & [meri] \\
\hline 3 & Could say & [kvd sei] & [kvt ter $]$ \\
\hline 4 & Taught me & [tot mi] & [tam mi] \\
\hline 5 & Love & {$[1 \Lambda \mathrm{v}]$} & [lof] \\
\hline 6 & $\mathrm{Me}$ & {$[\mathrm{mi}]$} & [mbi], [mar] \\
\hline 7 & Patience & [per`əns] & [per」ən] \\
\hline 8 & Amazing & [ə'meızın] & [ə'meisin] \\
\hline 9 & Lost & [lost $]$ & [los $]$ \\
\hline 10 & I & [aI] & [aIf] \\
\hline 11 & Thank & {$[\theta æ \eta \mathrm{k}]$} & {$[\theta$ enk $]$} \\
\hline 12 & Next & [nekst] & [ncks] \\
\hline 13 & Havin & [hævin] & [hefin] \\
\hline 14 & Discussions & [dI'sk $\left.\Lambda \int \partial n z\right]$ & [dI'sk $\left.\Lambda \int \partial n\right]$ \\
\hline 15 & Fast & [fæst] & [fæs] \\
\hline 16 & Forbid & [fər'bId] & [fər'bit] \\
\hline 17 & Least & [list] & {$[1 \varepsilon s]$} \\
\hline
\end{tabular}

In the word got, there was a change of vowel [a] to vowel [e]. In the word married, there was a change of vowel $[\mathfrak{x}]$ to vowel $[\varepsilon]$ and the consonant $[\mathrm{d}]$ was deleted. While in the words could say, the consonant [d] and consonant [s] were substituted with consonant [t]. The vowel [o] was substituted with vowel [a] and consonant $[\mathrm{t}]$ was substituted with consonant $[\mathrm{m}]$ and in the words taught me. In the word love, there was a change of vowel $[\Lambda]$ to vowel $[\mathrm{o}]$ and the consonant $[\mathrm{v}]$ 
was also susbtituted with consonant [f]. Besides that, the consonant [b] was inserted in the middle of the word $m e$. In the word $m e$, the vowel [I] was substituted with diphthong $[\mathrm{ar}]$. The consonant $[\mathrm{z}]$ was substituted with consonant $[\mathrm{s}]$ in the word amazing. The consonant $[\mathrm{t}]$ was deleted in the word lost. Meanwhile, the consonant [f] was inserted at the end of word $I$. In the word thank, the vowel [æ] was substituted with vowel [e]. The consonant [t] was deleted in the word next. In the word havin, the vowel [æ] was substituted with vowel [e] and the consonant [v] was substituted with consonant [f]. Other than that, the consonant [s] was deleted in the word discussions. The consonant $[\mathrm{t}]$ was also deleted in the word fast. The consonant [d] was substituted with consonant [t] in the word forbid.

The Third Indonesian Cover-singer (HD)

The third Indonesian cover-singer named HD sang a song titled "Comethru" by Jeremy Zucker. In singing the song, the researcher found that there were 12 words that pronounced differently by the third Indonesian cover-singer.

Table 3. The list of third Indonesian cover-singer's pronunciation

\begin{tabular}{|c|c|c|c|}
\hline No & English Words & $\begin{array}{l}\text { The Original Singer's } \\
\text { Pronunciation }\end{array}$ & $\begin{array}{l}\text { The Third } \\
\text { Indonesian Cover- } \\
\text { singer's } \\
\text { Pronunciation }\end{array}$ \\
\hline 1 & Lose & [luz] & [lus] \\
\hline 2 & Mind & [maind] & [main] \\
\hline 3 & $\mathrm{Be}$ & [bi] & [bif] \\
\hline 4 & Own & [oun] & [ov] \\
\hline 5 & Imagination & [Imædzə' neIfən] & [Imadzə' neISən] \\
\hline 6 & Come & {$[\mathrm{k} \wedge \mathrm{m}]$} & [kom] \\
\hline 7 & Old & [ould] & [ool] \\
\hline 8 & Bed & [bed] & [bet] \\
\hline
\end{tabular}




\begin{tabular}{llll}
9 & Patiently & {$[$ peIfəntli] } & {$[$ pefəntli] } \\
\hline 10 & Same & {$[$ seIm $]$} & {$[$ sem $]$} \\
\hline 11 & Faces & {$[$ feIsəz] } & {$[$ feIs $]$} \\
\hline 12 & Need & {$[$ nid $]$} & {$[$ nit $],[$ ni $]$}
\end{tabular}

In the word lose, there was a change of consonant [z] to consonant [s]. The consonant [d] was deleted in the word mind. The consonant [f] was inserted at the end of word be. Meanwhile, the consonant [n] was deleted in the word own. In the word imagination, the vowel [æ] was changed to vowel [a]. The vowel $[\Lambda]$ was changed to vowel [o] in the word come. The consonant [d] was deleted in the word old. While the consonant [d] was substituted with consonant $[\mathrm{t}]$ in the word bed. The dipthong [eI] was changed to vowel [e] in the word patiently and same. In the word faces, the sound [əz] is deleted. In the last, the consonant [d] was changed to consonant $[\mathrm{t}]$ in the word need.

\section{The Phonological Processes of the Indonesian Cover-singers' Pronunciation}

The First Indonesian Cover-singer (RM)

When the first Indonesian cover-singer pronounced the words differently from the original singer, as a result, there were 6 kinds of phonological processes that occurred. They were consonant deletion, vowel shift, consonant neutralization vowel coalescence, consonant insertion, and metathesis.

Consonant Deletion: There are 14 cases of consonant deletion. In the words here's, cheers, there's, and hurts the consonant [r] is deleted in the medial position. This confirms the finding of Jelangpaska (2020) in which he states that the consonant $[\mathrm{r}]$ in English and Bahasa Indonesia is pronounced in different way of manner of articulation. In English, the consonant [r] is considered as voiceless liquid and it is pronounced not too clear. While the consonant $[r]$ in Bahasa Indonesia is considered as voiced trill with a clear pronunciation. In the word ones and sometimes, the consonant $[\mathrm{z}]$ is deleted in the final position. This condition occurs because the distinction between the place of articulation of consonant /z/ in Bahasa Indonesia 
and English. This is in line with the theory from Alwi et al. (2017) that consonant [z] in Bahasa Indonesia is produced in palatal in the place of articulation. Meanwhile In English, the consonant [z] is produced with alveolar. In the words toast and lost, the consonant $[\mathrm{t}]$ is deleted in the final position. In the word stay, the consonant $[\mathrm{t}]$ is also deleted in the medial position. Meanwhile the consonant [t] in the medial position of the word it's is deleted. In the word hurts and drinks, the consonant [s] is deleted in the final position. And the last, the consonant $[\mathrm{n}]$ is deleted in the final position of the words an and gone.

Vowel Shift: There are 7 cases of vowel shift found in the first Indonesian coversinger's pronunciation. The words that undergo vowel shift are the, here, back, been, of, hatred, and an. In the word the, the vowel [ə] is pronounced as [v]. The tongue position of English vowel [ə] is in mid central while the vowel [v] is in high back. The first Indonesian cover-singer tends to substitute the vowel [ə] into [ $\mho]$ because the influence of the previous word, to. As the result, she also generalizes the vowel [ə] in the word the with the vowel [v] as in the previous word, to. In the word here, the first Indonesian cover-singer substitutes high front vowel $[I]$ with mid front vowel $[\varepsilon]$. Another vowel shift occurs in the word back and an. The vowel [æ] is substituted with vowel $[\varepsilon]$ in the word back. Meanwhile, the vowel [æ] is substituted with [ə] in the word an. The tongue position of English vowel [æ] is in low front, the vowel $[\varepsilon]$ is in mid front, and the schwa [ə] is in mid central. This supports the theory from Alwi et al. (2017) that the vowel [æ] in Bahasa Indonesia is absent. Therefore, she tries to find the similar vowel of [æ] in English until she tends to pronounces [bek] instead of [bæk] in the word back and [ə] instead of [æn] in the word $a$. In the word been, the vowel [I] is substituted with vowel [c]. The tongue position of vowel [I] is in high front while the position of vowel $[\varepsilon]$ is in mid front. The first Indonesian cover-singer substitutes the vowel $[\mathrm{I}]$ to $[\varepsilon]$ because she relies on the spelling of the word been itself and she used to pronounce it the way it is pronounced in Bahasa Indonesia. In English, the letter "e" can represent the vowels $[\varepsilon]$ and [I]. Meanwhile, in Bahasa Indonesia, the letter "e" can represents the vowels $[\varepsilon]$, [I], and [ə]. This confirms Hewings's theory that there is no relation between 
sound and letter in English (Martin, 2004). The next case of vowel shift is also found in the word $o f$. When pronouncing the word of, the first Indonesian cover-singer changed the vowel $[\Lambda]$ into [o]. The tongue position of vowel $[\Lambda]$ is in mid front, while mid back is the tongue position of vowel [o]. This is also in line with theory from Alwi et al. (2017) that there is no vowel $[\Lambda]$ in the Bahasa Indonesia phonological system. In addition, the Indonesian cover-singer is still influenced by the way she pronounces in Bahasa Indonesia in which the letter "o" is only represented by the vowel [o]. It is different from English in which the letter "o" can be pronounced with vowels $[0],[0]$, and $[\Lambda]$.

Consonant Neutralization: There are 6 words that undergo consonant neutralization namely cheers,cause, there's, of, hatred, and never. In the word cheers, cause, and there's, the first Indonesian cover-singer neutralizes the voiced consonant $[\mathrm{z}]$ is into voiceless consonant [s]. It occurs because in English, the letter "s" can represent consonant [s] and [z] while in Bahasa Indonesia, the letter "s" only represents consonant [s]. Pallawa (2013) confirms that the the letter "s" is represented as consonant $[\mathrm{s}]$ in Bahasa Indonesia. In addition, the place of articulation to produce the consonant $[\mathrm{z}]$ between English and Bahasa Indonesia is different. In English, the consonant $[\mathrm{z}]$ is produced in alveolar while in Bahasa Indonesia, it is produced in palatal. Meanwhile, the consonant [d] in the word hatred is neutralized with consonant [t]. This is also in line with the finding of Pallawa (2013) study that the letter " $d$ " in Indonesian is represented by consonant [t] in the final position of word. Another consonant neutralization is in the word of and never. The first Indonesian cover-singer neutralizes the voiced consonant [v] into voiceless consonant [f]. In this case, Alwi et al. (2017) states that there is no existence of consonant $[\mathrm{v}]$ in the Bahasa Indonesia phonological system.

Vowel Coalescence: There are 4 words that can be categorized as vowel coalescence in the first Indonesian cover singer's pronunciation. The words are toast, now, no, and hatred. The first Indonesian cover-singer tends to pronounce [tus] instead of [toust] in the word toast and [nof] instead of [nov] in the word no. Here, the first Indonesian cover-singer substitutes the diphtong [oo] into a single 
vowel [u]. Alwi et al. (2017) confirms that there is no existence of diphtong [ov] in the Bahasa Indonesia phonological system. Therefore, the first Indonesian coversinger finds the closest sound of [ov] to make her easier to pronounce the word toast and no. In the word now, there is also occur vowel coalescence. The first Indonesian cover-singer changes the diphtong [av] into a single vowel [o]. Both English and Bahasa Indonesia have diphtong [av] in the phonological system. In addition, the letter "ow" in Bahasa Indonesia does not represent the diphthong [av] as what English has. Therefore, the first Indonesian cover-singer tends to pronounce the word now as what she has seen in the orthography of the word now. Another vowel coalescence is in the word hatred. In this case, the first Indonesian cover-singer still accustomed to use the English vowel $[\varepsilon]$ as represented in the letter "a", in pronouncing diphthong [eI] in the word hatred.

Consonant Insertion: There are 2 cases of consonant insertion. First, the consonant $[\mathrm{t}]$ is inserted in the final position of through. Second, the consonant [f] is inserted in the final position of no.

Metathesis : There is only one word that undergoes metathesis namely felt. The first Indonesian cover-singer substitutes the final consonant cluster "lt" in the middle position of the word felt. This confirms Nuraini (2012) finding, in which she finds that in Bahasa Indonesia, the consonant cluster "lt" only appears in the medial position of a word, while in English, the consonant cluster "lt" appears in the final position. Therefore, the first Indonesian cover-singer does metathesis in the word felt to facilitate the pronunciation.

\section{The Second Indonesian Cover-singer (AH)}

When the second Indonesian cover-singer pronounced the words differently from the original singer, as a result, there were 6 kinds of phonological processes that occurred. They were consonant deletion, vowel shift, consonant neutralization, consonant insertion, assimilation, and diphtongization.

Consonant Deletion: There are 7 words that undergo consonant deletion. They are married, patience, lost, next, fast, discussions, and least. In the word married, the 
consonant [d] is deleted. This condition occurs because consonant [d] in Bahasa Indonesia only appears in initial and medial position (Pallawa, 2013). The consonant [t] in the word lost, next, fast, and least is deleted. In the word patience, the consonant [s] is deleted. Meanwhile, the consonant $[\mathrm{z}]$ in the word discussions is also deleted.

Vowel Shift: There are 7 words that undergo vowel shift namely got, married, taught, love, thank, havin and least. In the word got, the second Indonesian coversinger substitutes the vowel [a] into [e]. The position of vowel [a] which is in low central is substituted with vowel [e] in mid front position. In the word married, the position of vowel [æ] which is in low front is substituted with vowel $[\varepsilon]$ in mid front position. This condition happens because there is no vowel [æ] in Bahasa Indonesia phonological system. Then, the low back vowel [0] is substituted with low central vowel [a] in the word taught. This condition occurs because the Indonesian coversinger relies on the orthography of the word taught. In the word love, the second Indonesian cover-singer substitutes the vowel $[\Lambda]$ into [o]. This supports the theory from Alwi et al. (2017) that vowel $[\Lambda]$ does not appear in the Bahasa Indonesia phonological system. Hence, the second Indonesian cover-singerfinds the closest sound to facilitate her pronunciation. In the word least, the secondIndonesian coversinger tends to pronounce vowel [lest] instead of [list]. Here, the tongue position of [ع] which is in the high front is substituted with vowel [i] which is in the mid front position. The last vowel shift occurs in the word thank and havin. As the same with vowel $[\Lambda]$, this also confirms the theory from Alwi et al. (2017) that there is no vowel [æ] in Bahasa Indonesia phonological system. Hence, the second Indonesian cover-singer tends to substitute the vowel [æ] with vowel [e] which approximately the same as vowel [æ] in English.

Consonant Neutralization: There are 5 words that undergo consonant neutralization, namely could, love, amazing, havin, and forbid. In the words could and forbid, the second Indonesian cover singer neutralizes the voiced consonant [d] into voiceless consonant [t]. This in line with the finding of Pallawa (2013) study that the letter " $d$ " in Indonesian is represented by consonant $[t]$ in the final position 
of word. In the medial position of word amazing, the consonant [z] is neutralized with consonant [s]. Meanwhile, in the words love and havin, the second Indonesian cover- singer also neutralizes the voiced consonant [v] into voiceless consonant [f]. This confirms Alwi's theory that there is no existence of consonant [v] in the Bahasa Indonesia phonological system (Alwi et al., 2017).

Consonant Insertion : There are 2 words that undergo consonant insertion, they are $m e$ and $i$. The consonant $[\mathrm{b}]$ is inserted in the medial position of the word me. While in the word $i$, the consonant [f] is inserted in the final position.

Assimilation: There are 2 words that considered as assimilation. In the words taught $m e$, the consonant $[\mathrm{t}]$ is substituted with consonant $[\mathrm{m}]$. This condition happens because of the influence of the consonant [m] in the next word, me. Another word that undergo assimilation is could say. At first, the second Indonesian cover-singer does the neutralization at the final position of the word could, hence it is pronounced as [kot] instead of [kvd]. After that, she assimilates the consonant [s] in the word say with consonant $[\mathrm{t}]$.

Diphtongization: There is only a word that considered as diphtongization, it is the word me. The second Indonesian cover-singer tends to pronounce [maI] instead of [mi]. Here, the single vowel [i] is changed to diphong [ar].

\section{The Third Indonesian Cover-singer (HD)}

There were 5 types of phonological processes that occured when the third Indonesian cover-singer sung the song titled "Comethru". The phonological processes were consonant deletion, consonant neutralization, vowel shift, vowel coalescence, and consonant insertion.

Consonant Deletion: There are 5 consonant deletion found in the third Indonesian cover-singer's pronunciation namely mind, own, old, faces, and need. All the sounds are deleted in the final position of those words. In the words mind, old, and need, the consonant [d] is deleted. This condition occurs because consonant [d] in Bahasa Indonesia only appears in initial and medial position (Pallawa, 2013). The consonant 
[n] in the word own is also deleted. Meanwhile, the allomorph "ez" is also deleted in the word faces.

Consonant Neutralization: There are 3 words that undergo consonant neutralization, namely lose, bed, and need. In the word lose, the voiced consonant $[\mathrm{z}]$ is substituted with voicelss consonant [s] in the final position. It confirms the finding from Pallawa (2013) study that the the letter " $\mathrm{s}$ " in is represented as consonant $[\mathrm{s}]$ in Bahasa Indonesia. The consonant neutralization also occurs in the words bed and need. This is also in line with the finding of Pallawa (2013) study that in Bahasa Indonesia, letter " $d$ " is represented with consonant $[t]$ in the final position of the word. The voiced consonant [d] in Bahasa Indonesia is formed by placing the tip of tongue slighly backwards than voiceless consonant $[t]$. Hence, it is difficult for the third Indonesian cover-singer to pronounce the consonant $[d]$ in the final position of English word.

Vowel Shift : There are 2 words that undergo vowel shift namely come and imagination. In the word come, the third Indonesian cover-singer tends to pronounce $[\mathrm{kom}]$ instead of $[\mathrm{k} \Lambda \mathrm{m}]$. Here, the mid central vowel $[\Lambda]$ is substituted with mid back vowel [o]. Furthermore, the letter "o" in Bahasa Indonesia only represent vowel [o]. This is in line with the theory from Martin (2004) that there is no relation between sound and letter in English. In addition, there is no existence of vowel $[\Lambda]$ in the Bahasa Indonesia phonological system. The vowel shift also occurs in the word imagination. The third Indonesian cover-singer pronounces it as [Imadzo'nerfən] not [Imædzə' neIfən]. Here, the low front vowel [æ] is changed to low central vowel [a]. In addition, the letter "a" in Bahasa Indonesian only represents vowel [a]. These condititions also in line with the theory from Alwi et al. (2017) that vowels $[\Lambda]$ and [æ] in English do not appear in the Bahasa Indonesia phonological system.

Vowel Coalescence: There are 2 words that undergo vowel coalescence. Those words are same and patiently. The diphtong [er] in the initial position of the words same and patiently is deleted. Even though both Bahasa Indonesia and English have the diphtong [eI] in the phonological system, but the third Indonesian cover-singer tends to substitute the diphtong [er] with a single vowel [e]. 
Consonant Insertion: There is only one word that undergoes a consonant insertion. It is found in the word be. The third Indonesian cover singer adds the consonant [f] to the ending position of the word be. The insertion of the consonant [f] in the final position occurs to make it easier for the third Indonesian cover-singer in pronouncing the word be and the next word, fine.

\section{CONCLUSIONS AND SUGGESTIONS}

\section{Conclusions}

Based on the finding and the discussion of the study, there are several sounds as well as the phonological process occurs when the Indonesian cover-singers singing English songs on the YouTube channel. At the first Indonesian coversinger's pronunciation, there were 26 words that experienced pronunciation changes, then at the second Indonesian cover-singer pronunciation, there were 17 words that experienced pronunciation changes, and at the third Indonesian -singer's pronunciation, there were 12 words that experienced pronunciation changes. In addition, there are several phonological process as a result of the pronunciation changes made by Indonesian cover-singers when they singing English songs on the YouTube channel. The first Indonesian cover-singer performs 6 types of phonological processes namely consonant deletion, vowel shift, consonant neutralization, vowel coalescence, consonant insertion, and metathesis. Then, the second Indonesian cover-singer also performs 6 types of phonological processes, such as consonant deletion, vowel shift, consonant neutralization, consonant insertion, assimilation, and diphthongization. The last one is the third Indonesian cover-singer who performs 5 types of phonological processes, such as consonant deletion, consonant neutralization, vowel shift, vowel coalescence, and consonant insertion. Uniquely, the phonological process that was mostly carried out by the three Indonesian cover-singers was the consonant deletion.

The Indonesian cover-singers' pronunciation changes along with the phonological processes occur due to the two reasons. The first reason is because of the distinction in the phonological system between Bahasa Indonesia and English. There are several English sounds from consonant, vowel, and diphthong that are Ismi Maulina Utami 
pronounced differently by Indonesian cover-singers, which apparently the sounds do not exist in the Bahasa Indonesia phonological system. In terms of consonants, in Bahasa Indonesia, there is no consonant [v]. Hence, the Indonesian cover-singers often neutralize the consonant [v] with the consonant [f]. In addition, there is also a distinction in the place and manner of articulation in the Bahasa Indonesia and English phonological systems. In English, the consonant $[\mathrm{z}]$ is produced in alveolar, while in Bahasa Indonesia, it is produced in palatal. The distinction in the place of articulation when pronouncing the sound [z] makes the Indonesian cover-singer also neutralizes the sound $[\mathrm{z}]$ with $[\mathrm{s}]$. Then, the consonant $[\mathrm{d}]$ is also often pronounce as consonant $[\mathrm{t}]$ by the Indonesian cover-singer. This is because the consonant $[\mathrm{d}]$ in the final position in a word tends to be pronounced with the consonant [t]. Unlike Bahasa Indonesia, in English, the consonant [d] can be pronounced either the consonant $[\mathrm{d}]$ or $[\mathrm{t}]$. Furthermore, there is also a distinction in the manner of articulation between consonant $[\mathrm{r}]$ in English and Bahasa Indonesia. The consonant [r] in English is considered a voiceless liquid and it is pronounced not too clear. Meanwhile, consonant [r] in Bahasa Indonesia is pronounced clearly and it is considered as consonant voiced trill. As the result, this condition often makes the Indonesian cover-singers to delete the consonant $[\mathrm{r}]$ in the final position of a word.

In terms of vowels and diphthongs, there are several sounds that do not exist in the Bahasa Indonesia phonological system. The sounds are [æ], $[\Lambda]$, and [oø]. This kind of conditions make Indonesian cover-singers to replace the non-existent sounds with sounds they are familiar with in Bahasa Indonesia. Moreover, there are some sounds that exist in both English and Bahasa Indonesia phonological system, but they appear in a different position. For example, in English, the consonant cluster "It" only occurs in the final position. Meanwhile, in Bahasa Indonesia, the consonant cluster "lt" only occurs in the medial position. Hence, the Indonesian cover-singer tends to reverse the order of the word felt into flet. The second reason of the pronunciation changes is that Indonesian cover-singers still rely on the word's spelling. This condition occurs because in Bahasa Indonesia, the pronunciation of vowel [a] is the same as a letter written in a word. For example, the letter "a" in 
Bahasa Indonesia represents the sound [a]. In contrast to Bahasa Indonesia, the letter "a" in English can represent sound [e], [ع], [ə], or [æ]. Apart from the two reasons that make the pronunciation change when the Indonesian cover-singers sing English song, it also can be found that there are some sounds that still exist in the two languages (English and Bahasa Indonesia), but there is a similarity in the manner and place of articulation in a sound, also the similarity in the emergence of each sound in the three positions of a word. However, the Indonesian cover-singers still frequently do the pronunciation changes.

\section{Suggestions}

The results of this study are expected to broaden the area of linguistic, especially in the pronunciation of Indonesian singers when they singing English songs. With this study, it is expected to trigger the Indonesian cover-singers to sing the English songs with correct pronunciation by listening to the English songs in several times. In addition, the Indonesian cover singers' should improve the knowledge in speaking English. For the future study, the researcher expects more detailed analysis with another subject by using a different theory in phonology or another approach of linguistics.

\section{REFERENCES}

Alwi, H., Dardjowijojo, S., Lapoliwa, H., Moeliono, A. (2017). Tata Bahasa Baku Bahasa Indonesia Edisi Keempat.

Carr, P. (2008). A Glossary of Phonology.

Fraser, H. (2001). Teaching Pronunciation: A handbook for Teachers and Trainers.

Fromkin, V., Rodman, R., \& Hyams, N. (2014). An Introduction to Langauge 10th Edition.

Hancock, D. R. (2018). Doing Case Study Research. In Dalton Transactions (Vol. 47).

Jelangpaska, I. H. (2020). Indonesian Singer Consonants Pronunciation in Klif's Fancy Lady and Red Cigarette.

Khumaidi, M. I. (2020). Phonological Perspective on Pronunciation Changes of Metal Vocal Techniques

Martin, H. (2004). Pronunciation Practice Activities. A Resource Bookfor Teaching English Pronunciation.

Ismi Maulina Utami

LET: Linguistics, Literature and Language Teaching Journal Vol. 11 No. 12021 
Mattew B.Miles, A.Michael Huberman, Saldana, J. (2014). Qualitative Data Analysis.

Nuraini, E. (2012). A Comparative Study on English and Indonesian Consonant Clusters.

Odden, D. (2005). Introducing Phonology.

Pallawa, A. (2013). A Comparative Analysis between English and Indonesian Phonological Systems. International Journal of English Language Education, $1(3)$.

Peter Avery, S. E. (2013). Teaching American English Pronunciation.

Schane, S. A. (1973). Generative Phonology.

Simangunsong, Y. G. (2018). Mispronunciation of English Front Vowels by the Sixth Semester Students on Non-English Department of Sanata Dharma University

Wahyuni, A. K. T. (2012). Phonological Analysis on Labiodental Fricatives Produced by South Korean Singers in Live Performance Music Video.

Wolfram, W., \& Johnson, R. (1984). Phonological Analysis: Focus on American English.

Yule, G. (2006). The Study of Language.

Ismi Maulina Utami

LET: Linguistics, Literature and Language Teaching Journal Vol. 11 No. 12021 